\title{
Risk of oral and gastrointestinal mucosal injury among patients receiving selected targeted agents: a meta-analysis
}

\author{
Linda S. Elting • Yu-Chia Chang • Pratibha Parelkar • Christine B. Boers-Doets • \\ Marisol Michelet • Guido Hita • Tanya Rouleau • Catherine Cooksley • Josiah Halm • \\ Madhuri Vithala • Paolo Bossi • Carmen Escalante • Michael T. Brennan • \\ On behalf of the Mucositis Study Group of the Multinational Association \\ of Supportive Care in Cancer/International Society of Oral Oncology (MASCC/ISOO)
}

Received: 18 December 2012 / Accepted: 11 April 2013 /Published online: 2 May 2013

(C) Springer-Verlag Berlin Heidelberg 2013

\begin{abstract}
Purpose The purpose of this study was to estimate the risk and severity of oral and gastrointestinal mucosal toxicities associated with selected targeted agents.

Methods We searched the English-language literature in February 2011 for reports of randomized clinical trials comparing a FDA-approved targeted agent to a standard of care regimens. Long-term follow-up and secondary reports of trials were excluded, leaving 85 studies for analysis. Using metaanalytic methods, we calculated the relative risks of oral and gastrointestinal toxicities, adjusting for sample size using the inverse variance technique. For each targeted agent and each side effect, we calculated the number needed to harm, the
\end{abstract}

L. S. Elting $(\bowtie) \cdot$ Y.-C. Chang $\cdot$ P. Parelkar

Department of Health Services Research, The University of Texas MD Anderson Cancer Center, 1400 Pressler St., Unit 1444,

Houston, TX 77030-4009, USA

e-mail: lelting@mdanderson.org

\section{B. Boers-Doets}

Department of Clinical Oncology, Leiden University Medical

Centre, PO Box 9600, 2300 RC, Leiden, The Netherlands

\section{Michelet}

Oral Medicine Department, FUNDALEU-Foundation to Fight against Leukemia, Hospitalization and Clinical Research Center, José E. Uriburu 1450,

Buenos Aires, Argentina

G. Hita $\cdot$ J. Halm

Department of General Internal Medicine, The University of Texas MD Anderson Cancer Center, 1515 Holcombe Blvd., Unit 1465, Houston, TX 77030, USA

\section{T. Rouleau}

Department of Oral Medicine, Carolinas Medical Center, PO Box

32861, Charlotte, NC, USA number of patients that, if treated with the more toxic regimen, would produce one additional episode of the toxicity.

Results Oral mucositis was significantly more frequent among patients treated with bevacizumab, erlotinib, sorafenib, or sunitinib, although this difference was confined to low-grade mucositis. The clinical significance of these findings is unclear given its low incidence and mild severity. In contrast, diarrhea was significantly more frequent with most of the targeted agents studied, with adjusted relative risks between 1.5 and 4.5. An additional patient with diarrhea will be observed for every three to five patients treated with these targeted agents, compared with conventional regimens.

\section{Cooksley}

Department of Internal Medicine, University of Texas Medical Branch, 301 University Blvd.,

Galveston, TX 77555-0177, USA

M. Vithala

Division of Medical Oncology, Duke University Medical

Center/Durham VA Medical Center, 508 Fulton St.,

Durham, NC 27705, USA

P. Bossi

Head and Neck Medical Oncology, Fondazione IRCCS Istituto Nazionale dei Tumori, Via Venezian 1,

Milan, Italy

\section{Escalante}

Department of General Internal Medicine, The University of Texas MD Anderson Cancer Center, 1400 Pressler St., Unit 1465,

Houston, TX 77030-4004, USA

\section{T. Brennan}

Department of Oral Medicine, Carolinas Medical Center, 1000

Blythe Blvd.,

Charlotte, NC 28203, USA 
Conclusions Oral mucosal toxicities occasionally complicate treatment with these targeted agents, but the clinical significance of this finding is not clear. Diarrhea is a hallmark of treatment with these targeted agents; this side effect should be carefully ascertained to permit early intervention and control.

Keywords Mucositis $\cdot$ Stomatitis $\cdot$ Diarrhea $\cdot$ Targeted therapy $\cdot$ Toxicity $\cdot$ Meta-analysis $\cdot$ Systematic review

\section{Introduction}

Oral and gastrointestinal mucosal injuries commonly complicate antineoplastic chemo- and radiation therapy. These complications disrupt delivery of planned therapy and adversely affect quality of life, utilization of healthcare resources, and the cost of care [1-5]. The MASCC/ISOO Clinical Practice Guideline for the Prevention and Treatment of Mucositis was developed to provide recommendations for the prevention and management of these significant complications [6, 7]. In concert with the current update of those guidelines, we reviewed the risks of these complications associated with selected targeted agents.

Over the past 15 years, targeted therapies, which include monoclonal antibodies and small molecule inhibitors, have significantly changed the treatment of cancer [4, 8]. Many are routinely used to treat common malignancies, including breast, colorectal, gastric, lung, head and neck, lymphoma, leukemia, pancreatic, and multiple myeloma. Targeted therapy improves survival but toxicities remain $[9,10]$.

The adverse effects caused by targeted agents include fatigue, diarrhea, rash, nausea, cardiovascular toxicity, neutropenia, and mucositis [4]. Clinical trials of targeted agents have reported these toxicities, but with the exception of cutaneous toxicities [11], systematic examinations of their risks and severity are lacking. Furthermore, the sample sizes achieved in individual trials rarely support the examination of the risk of rarely occurring adverse events. As utilization of targeted agents continues to expand, such a systematic evaluation is critical to understanding the effectiveness and harms associated with these agents. To fulfill this need, we conducted a meta-analysis of clinical trials of Food and Drug Administration (FDA)-approved targeted agents to estimate their incremental risks and severity of oral and gastrointestinal mucosal toxicities.

\section{Methods}

Search strategy

We identified studies of 26 targeted cancer therapy drugs approved by FDA as of November 2010 (Table 1) that had
Table 1 FDA-approved targeted therapies for cancer

\begin{tabular}{|c|c|}
\hline Drug name & Approved indication \\
\hline Alemtuzumab & B-cell CLL \\
\hline Bevacizumab & Glioblastoma, NSCLC, met CRC, breast cancer \\
\hline Bexarotene & CTCL \\
\hline Bortezomib & Multiple myeloma, mantle cell lymphoma \\
\hline Cetuximab & CRC, SCCHN \\
\hline Dasatinib & CML, ALL \\
\hline $\begin{array}{l}\text { Denileukin } \\
\text { difitox }\end{array}$ & CTCL \\
\hline Erlotinib & NSCLC, pancreatic cancer \\
\hline Everolimus & $\begin{array}{l}\text { Advanced RCC, subependymal giant cell } \\
\text { astrocytoma, pancreatic neuroendocrine tumors }\end{array}$ \\
\hline Gefitinib & NSCLC \\
\hline Ibritumomab & NHL \\
\hline Imatinib & GIST, leukemia \\
\hline Lapatinib & Advanced or metastatic breast cancer \\
\hline Nilotinib & CML \\
\hline Ofatumumab & CLL \\
\hline Panitumumab & Met CRC \\
\hline Pazopanib & Advanced RCC \\
\hline Pralatrexate & Peripheral T-cell lymphoma \\
\hline Rituximab & NHL \\
\hline Romidepsin & CTCL \\
\hline Sorafenib & Advanced RCC, hepatocellular carcinoma \\
\hline Sunitinib & Met RCC, GIST \\
\hline Temsirolimus & Advanced RCC \\
\hline Tositumomab & NHL \\
\hline Trastuzumab & Breast \\
\hline Vorinostat & CTCL \\
\hline
\end{tabular}

Source: Targeted Cancer Therapies - Fact Sheet. http://www.cancer.gov/ cancertopics/factsheet/Therapy/targeted. Accessed November 2010. This is a list of targeted therapies that were approved by FDA in 2010. However, there are other agents and indications being added to or removed from the list since then

$A L L$ acute lymphoblastic leukemia, $A M L$ acute myeloid leukemia, $C M L$ chronic myelogenous leukemia, $C R C$ colorectal cancer, $C T C L$ cutaneous T-cell lymphoma, GIST gastrointestinal stromal tumors, $N H L$ non-Hodgkin's lymphoma, $H N$ head and neck cancer, NSCLC non-small cell lung cancer, $R C C$ renal cell carcinoma, $S C C H N$ squamous cell carcinoma of the head and neck

been published in English between January 1, 2000 and February 28, 2011 in MEDLINE [12]. Keywords used were phase II or III randomized control trials, drug names (brand or generic), and their FDA-approved indications (Table 1). Gefitinib was withdrawn from the market in the USA on April 25, 2012 [13], midway through our analysis. However, since it continues to be used in the European Union, we have included it in this report [14]. We only included studies reporting the results of trials that compared targeted and standard of care regimens. In some cases, the standard of care was no therapy (post-adjuvant therapy of breast cancer or 
renal cell carcinoma). In those cases, the comparison is to placebo or no therapy. In most cases, the targeted regimen included conventional chemotherapy, reflecting common practice. In a few cases, most notably with the agent gefitinib, the targeted agent alone was compared with chemotherapy. Studies reporting results from interim or subset analysis, phase I and early phase II dose-findings studies, those without a control group receiving standard of care regimens, and those without toxicity data were excluded.

\section{Data extraction}

We recorded information about trial design, regimen, and oral and/or gastrointestinal mucosal toxicity for each study. Trial design included trial phase (II, III, and II-III). Treatment regimen information contained regimen (targeted therapy, chemotherapy, and/or radiotherapy) and total number of patients in each arm. Mucosal side effects included oral mucositis (OM) or stomatitis, oral and aphthous ulcers, esophagitis, diarrhea, gastritis, GI perforation/hemorrhage, and xerostomia. The toxicity assessment method, assessment frequency, total number of all-grade side effects, number of high-grade (grade 3/4/5) side effects, number of hospitalizations, and number of deaths were recorded.

\section{Statistical analysis}

Meta-analysis was performed using Comprehensive MetaAnalysis version 2 (CMA). Our analytical goal was to estimate the unique contribution of the targeted agent to the risk of mucosal complications. To achieve this, we first calculated the risk of each side effect for each trial as well as the overall adjusted risk for each drug as a weighted average of risk from different studies, where the weights were estimated using the inverse-variance method. We then calculated the risk difference between the targeted regimen and the standard of care regimen. Finally, we computed the relative risk of mucosal complications for each agent. We utilized a classic half-integer continuity correction to calculate relative risk and variance for studies reporting no events in the treatment or control group. The relative risks and their corresponding $95 \%$ confidence intervals were derived from CMA. Number needed to harm $(\mathrm{NNH})$, the reciprocal of the adjusted risk increase, was calculated to examine adverse events of targeted drugs [15].

For meta-analysis of each drug, Cochran's $Q$ statistic was calculated for assessing the heterogeneity of the trials included. The assumption of homogeneity was considered invalid when the $p$ value is less than 0.1 , and the pooled estimate calculated based on random-effects model was used. Otherwise, results from both fixed-effects and random-effects models were considered. A two-tailed $p$ value of less than 0.05 was considered to be statistically significant.
As previously mentioned, some control regimens involved no therapy, reflecting the standard of care. These studies were combined with others for analysis, but to account for the impact of this difference on the estimates of risk, we computed risk differences and relative risks rather than absolute risk. Relative risk and risk differences should provide accurate measures of the unique contribution of the targeted agent to any regimen (no therapy or chemotherapy) except in the case where the risk of mucosal complications with targeted plus conventional chemotherapy is multiplicative (rather than additive). We are not aware of any research suggesting such a relationship. In a few studies, particularly those involving gefitinib, single-agent targeted therapy was compared with conventional chemotherapy. The inaccuracy introduced by those studies is not controlled by the use of relative risk and risk differences. In that situation, we have provided two estimates, one for all studies combined and one from a parallel analysis that excluded single agent targeted therapy versus chemotherapy.

\section{Results}

Our planned search yielded 2,179 potentially relevant articles. After excluding review articles, economic evaluation articles, case reports, commentaries, single-arm trials, and phase I trials, as planned, 101 articles were identified for review [16-116]. Of these 101 articles, 20 were excluded for being follow-up or maintenance studies, or having no more than two studies associated with the targeted drug [40, 52, $70,73-75,77,89,96,100,104,106,109-116]$. At the conclusion of the planned search strategy, a total of 81 articles describing trials of eight targeted drugs remained (Fig. 1). The targeted agents included bevacizumab, cetuximab, erlotinib, gefitinib, lapatinib, rituximab, sorafenib, and trastuzumab. However, review of the excluded articles revealed the elimination of two agents considered of such clinical importance that their exclusion would be inappropriate. Consequently, we included two additional targeted agents, imatinib and sunitinib, each of which had only two qualified studies [109, 113-115]. With these additions, a total of 85 articles were included. The majority of the trials used either National Cancer Institute Common Toxicity Criteria versions 1,2 , or 3 to assess the severity of side effects, while a few trials used WHO Toxicity Criteria or National Cancer Institute of Canada Common Toxicity Criteria.

Oral mucositis or stomatitis

Based on analysis of 35 and 38 trials reporting all-grade and high-grade $\mathrm{OM}$, respectively, we conclude that $\mathrm{OM}$ is not a clinically important feature of treatment with the targeted agents studied (Table 2). A higher risk of all-grade OM was 
Fig. 1 Flow chart of literature search and trial selection process
Potential relevant articles using search terms

$(\mathrm{N}=2179)$

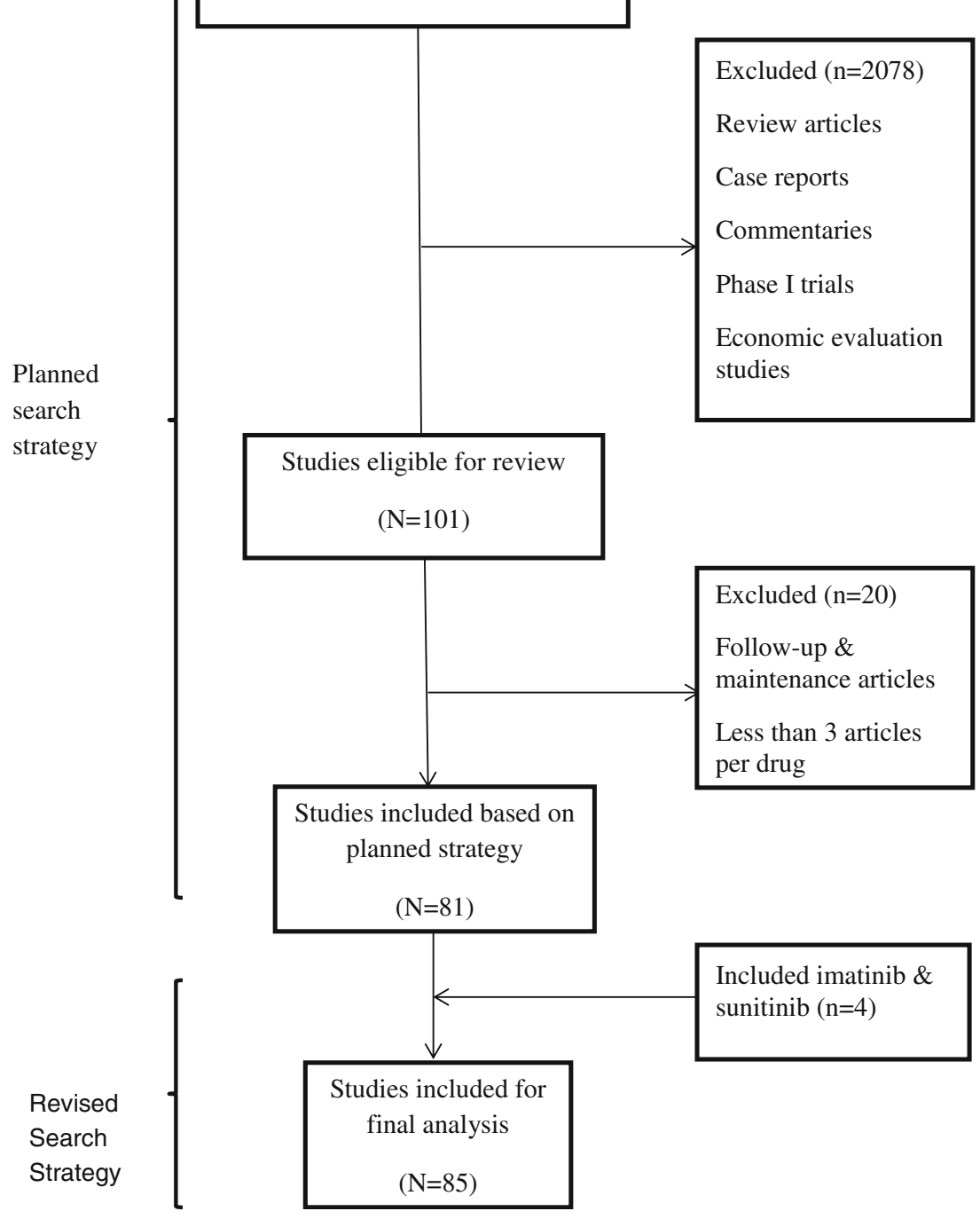

30, 35, 43-46, 92, 93, 114, 115]. For every five patients treated with bevacizumab, there was one additional allgrade OM compared to those patients in the control regimens. There was one additional all-grade OM for every nine patients treated with erlotinib compared to those in the control regimens. There was one additional all-grade OM for every four patients treated with sunitinib compared to those in the control regimens. In contrast, the adjusted risk of all-grade OM was significantly lower in the imatinib regimen compared to control regimen $(\mathrm{RR}=0.2, p<0.0001)$ [113]. As previously mentioned, the clinical significance of these differences is unclear as they are limited to relatively few cases of mild OM. With respect to other targeted drugs, there was no significant difference between targeted and control regimens for all-grade OM. 


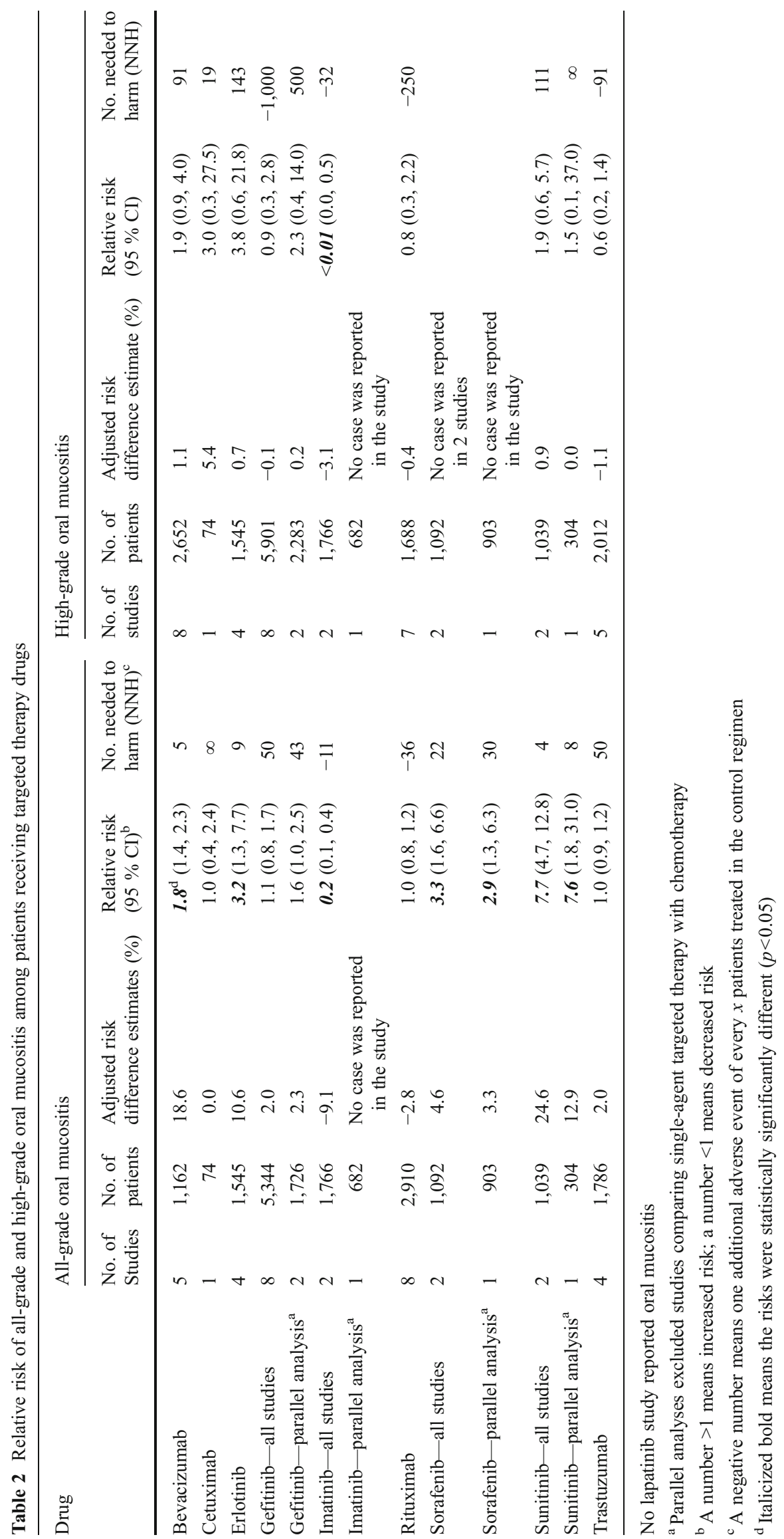


No significant difference was observed in the risk of high-grade OM between targeted and standard chemotherapy regimens, except in the case of imatinib which showed a significantly lower risk of high-grade $\mathrm{OM}(\mathrm{RR}=0.03$, $p=0.01$ ) [113]. Three other targeted agents also had lower risks of high-grade OM, but these differences did not reach statistical significance. OM was not reported in any of the three trials involving lapatinib [63-65].

\section{Diarrhea}

Forty-nine and 59 trials reported all-grade and high-grade diarrhea, respectively (Table 3). Diarrhea was the most frequently reported side effect among mucosal side effects. Seven targeted agents, bevacizumab, erlotinib, gefitinib, lapatinib, sorafenib, sunitinib, and trastuzumab, were associated with significantly increased risks of allgrade diarrhea compared with standard of care regimens $[19,22-24,26,29,30,34,35,41,43-51,53-59,61-65$, 91-94, 97, 102, 105, 114, 115]. The relative risks ranged from 1.1 to 4.1 . There was one additional all-grade diarrhea for every three patients treated with lapatinib or sorafenib compared to those treated with conventional regimens. The adjusted risks of all-grade diarrhea were significantly higher in the sunitinib regimen compared to control regimen $(\mathrm{RR}=4.0, p<0.0001)[114,115]$. There was one additional all-grade diarrhea of every two patients treated with sunitinib compared to those in the control regimen. No significant difference in the risk of all-grade diarrhea was observed between cetuximab and control regimens [37].

Six drugs, cetuximab, erlotinib, gefitinib, lapatinib, sorafenib, and sunitinib, were associated with significantly increased risks of high-grade diarrhea compared with control regimens [36-38, 41-51, 53-61, 63-65, 90-94, 114, 115]. The relative risk for lapatinib can be as high as 5.2. Patients treated with sunitinib are about eight times more likely to develop high-grade diarrhea than those who receive standard of care $(p<0.0001)$ [114, $115]$. Bevacizumab was not associated with an increased risk for high-grade diarrhea compared with control regimens [17, 19-25, 27, 29, 30, 32, 35].

Rituximab and imatinib demonstrated lower risks of allgrade and high-grade diarrhea compared with standard regimens, but this difference reached statistical significance only in the case of imatinib ( $\mathrm{RR}=0.7, p=0.03)[68,71,72$, $78,79,81,109,113]$. There was one additional all-grade diarrhea for every six patients treated with control regimens compared to those treated with imatinib.

As in the case of mucositis, parallel analyses of subsets of studies excluding those examining single-agent targeted therapy versus chemotherapy showed very consistent results when compared with analyses including all studies.
Other toxicities

Other mucosal toxicities, including GI perforation/hemorrhage, esophagitis, gastritis, oral and aphthous ulcers, and xerostomia, were reported rarely. Three and nine trials of bevacizumab reported all-grade and high-grade GI perforation/hemorrhage, respectively $[18,19,21,22,25,27,28,31-33]$. Two erlotinib trials and one sorafenib trial reported high-grade GI perforation/hemorrhage [42, 44, 90]. No statistically significant difference in risk of GI perforation was reported for any agent, although the power to detect differences in risk of such rare events may have been lacking, even in meta-analysis.

Only one trastuzumab trial reported esophagitis; no difference in risk was observed between trastuzumab and control arm [99]. One imatinib trial and one sunitinib trial reported all-grade and high-grade gastritis and two gefitinib trials reported all-grade gastritis [54, 62, 113, 115]. The overall adjusted risks of all-grade gastritis for imatinib and sunitinib regimens were significantly higher than those of control regimens (imatinib- $\mathrm{RR}=1.8, p=0.001$; sunitinib $-\mathrm{RR}=9.1, p<0.0001)$. One imatinib trial reported both all-grade and high-grade xerostomia [99]; the RR of xerostomia among patients treated with imatinib was significantly lower than those who received standard chemotherapy $(\mathrm{RR}=0.2, p<0.0001)$. Two sunitinib trials reported both allgrade and high-grade xerostomia $[114,115]$. The overall adjusted risk for sunitinib regimens of all-grade xerostomia was statistically significantly higher than that of control regimens $(\mathrm{RR}=2.1, p=0.002)$. No study reported a case of oral and aphthous ulcers.

\section{Discussion}

Our analysis shows that OM, gastritis, esophagitis, and xerostomia are occasional complications of therapy with the targeted agents that we studied, but these problems are not significantly more common or more serious than those observed with standard of care regimens. In contrast, diarrhea is a hallmark of therapy with several of these targeted agents, increasing the risk 2-8-fold compared with conventional regimens. An additional patient with diarrhea will be observed for every three to five patients treated with these targeted agents. Our results are consistent with prior reviews and case series on the topic. Keefe et al. indicated that diarrhea is a common side effect of targeted therapy and can cause severe diarrhea when these targeted drugs are used with chemotherapy [4]. Harandi et al. also pointed out that diarrhea is strongly associated with the use of anti-epidermal growth factor receptor tyrosine kinase inhibitors [117]. Other studies mentioned diarrhea as a common side effect as well $[118,119]$. Our analysis showed most of 


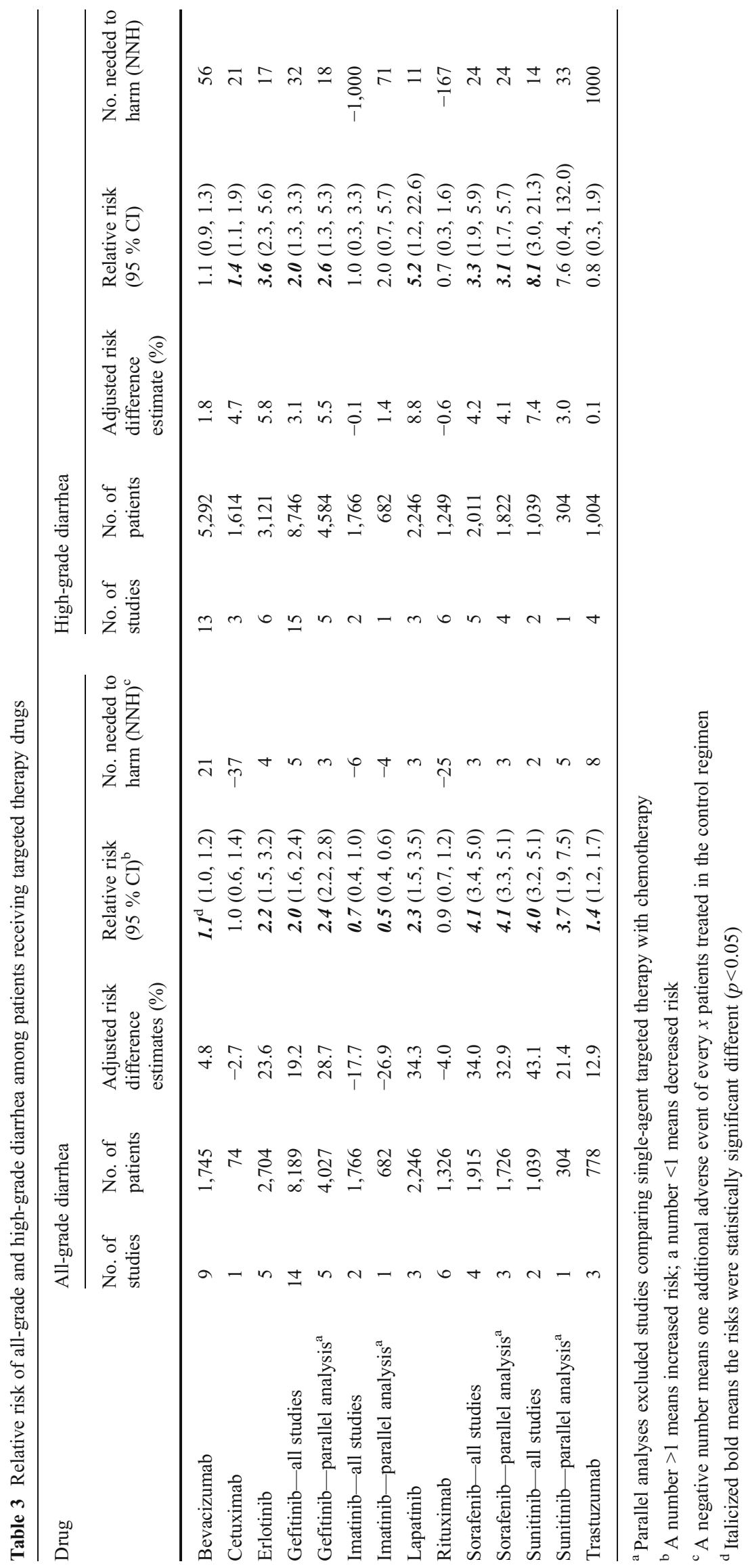


the targeted agents studied were associated with significantly higher risks of developing either all-grade or highgrade diarrhea than the conventional regimens. Patients treated with erlotinib, gefitinib, lapatinib, sorafenib, and sunitinib have significantly higher risk of having both allgrade and high-grade diarrhea than those in the conventional regimens, and the risk can be as high as 8-fold for patients treated with lapatinib. The mechanisms underlying diarrhea caused by targeted therapies have been less studied than those occurring with chemotherapy and research is needed in this field.

Ascertaining risk of complications from clinical trials of cancer therapy

Because studies designed to measure the risk of complications are lacking, we used data from anti-neoplastic therapy trials to conduct our meta-analyses. This strategy is known to be associated with underreporting of mucosal toxicities because these problems occur between cycles when monitoring is infrequent $[1,2,120,121]$. Furthermore, clinical trials rarely include patient reports of mucositis which leads to significant underreporting of complications [122]. Because we report only risk differences and relative risks, which should not be affected by underreporting, we believe our results are accurate. We know of no reasons that mucosal toxicity associated with targeted agents would be either more or less commonly reported than that associated with conventional therapy in the same randomized trial. Unfortunately, however, this situation compromises our ability to comment on the absolute risks of mucosal toxicity and, thus, the magnitude of the problem. (A relative risk of 2.0 describes the difference between rates of $4 \%$ and $2 \%$ as well as the difference between rates of $90 \%$ and $45 \%$.) Studies of toxicities incorporating patient-reported symptoms and frequent monitoring between cycles are needed to complete our picture of the risk of mucosal toxicities.

Our analysis is further limited in that its results apply only to the targeted agents studied. As can be seen from our analyses, the results varied in important ways among the different targeted agents studied and there are several other agents available that we have not studied.

Fast-track approval of breakthrough agents

Our analyses were limited by the small number of randomized clinical trials of some agents, a result, we believe, of fast-track approval of these promising agents (Table 4). Imatinib was approved in 2001, and there were only two randomized controlled trials that qualified for our review. Cetuximab and erlotinib were examined in four and six qualified studies, respectively.
Table 4 Fast-track approval targeted therapy drugs

\begin{tabular}{llc}
\hline Targeted therapy drugs (brand name) & Approval date & No. of studies \\
\hline Bevacizumab (Avastin) & $2 / 26 / 2004$ & $20^{\mathrm{a}}$ \\
Cetuximab (Erbitux) & $2 / 12 / 2004$ & 4 \\
Erlotinib hydrochloride (Tarceva) & $11 / 18 / 2004$ & 6 \\
Gefitinib (Iressa) & $5 / 5 / 2003$ & 15 \\
Imatinib (Gleevec) & $5 / 10 / 2001$ & 2 \\
Lapatinib (Tykerb) & $3 / 13 / 2007$ & 3 \\
Sorafenib tosylate (Nexavar) & $12 / 20 / 2005$ & 5 \\
Trastuzumab (Herceptin) & $9 / 25 / 1998$ & 10 \\
\hline
\end{tabular}

${ }^{a}$ Colorectal cancer indication, 12 trials; breast cancer indication, four trials; non-small cell lung cancer indication, four trials

Expedited approval processes were developed in the early 1990s and codified under the FDA Modernization Act in 1997 [123, 124]. They are critical to the rapid development and delivery of breakthrough drugs for potentially fatal illnesses for which other therapies are lacking. Among the provisions of the Act are mechanisms for provisional approval of an agent based on a single, uncontrolled trial if benefit is shown for a serious or life-threatening illness, provided post-marketing phase IV trials are conducted to confirm the original findings. Despite the benefits enjoyed by many patients, this process has the negative effect of providing little information about side effects, particularly those that are relatively rare. For example, seven early bevacizumab trials reported a total of eight cases of GI perforation that were fatal. Although the risk of death in the bevacizumab regimens was not significantly higher than the conventional regimens, this rare adverse event accounted for a large proportion of deaths in the early trials. In addition to the limited information provided by phase II-III trials of fast-track drugs, in many cases, phase IV, post-marketing studies have been slow to develop and often fail to include comparison groups [125]. Thus, the number of patients treated with targeted agents is insufficient to derive accurate estimates of incidence of rare side effects, even when trials are combined in meta-analysis.

We conclude by emphasizing three points. First, targeted agents that we studied are not associated with clinically significant increases in the risk or severity of most mucosal toxicities. The significantly increased risk of diarrhea is the notable exception to this rule. Second, the absolute incidence of mucosal toxicities with these targeted agents remains unclear because data derived from clinical trials are subject to severe underreporting. Finally, additional information from post-marketing studies is needed to estimate the risks of rare events with sufficient power and precision.

Acknowledgments We thank Ronald Hutchins, Senior Librarian at MD Anderson Cancer Center Research Medical Library, for providing invaluable assistance in conducting the literature search. 
Conflict of interest This research received no financial sponsorship from any funding agency in the public, commercial or not-for-profit sectors. We do have full control of all the primary data and agree to allow the journal to review the data if requested.

Dr. Elting has research funding from Helsinn Pharmaceutical Company.

\section{References}

1. Elting LS, Cooksley C, Chambers M et al (2003) The burdens of cancer therapy. Clinical and economic outcomes of chemotherapyinduced mucositis. Cancer 98(7):1531-1539

2. Sonis ST (2010) Regimen-related gastrointestinal toxicities in cancer patients. Curr Opin Support Palliat Care 4(1):26-30

3. Keefe DM, Gibson RJ (2007) Mucosal injury from targeted anticancer therapy. Support Care Cancer 15(5):483-490

4. Keefe DMK, Bateman EH (2012) Tumor control versus adverse events with targeted anticancer therapies. Nat Rev Clin Oncol 9(2):98-109

5. Elting LS, Cooksley CD, Chambers MS et al (2007) Risk, outcomes, and costs of radiation-induced oral mucositis among patients with head-and-neck malignancies. Int J Radiat Oncol Biol Phys 68(4):1110-1120

6. Rubenstein EB, Peterson DE, Schubert M et al (2004) Clinical practice guidelines for the prevention and treatment of cancer therapy-induced oral and gastrointestinal mucositis. Cancer 100(9 Suppl):2026-2046

7. Keefe DM, Schubert MM, Elting LS et al (2007) Updated clinical practice guidelines for the prevention and treatment of mucositis. Cancer 109(5):820-831

8. Keefe D, Stringer A (2010) The potential successes and challenges of targeted anticancer therapies. Curr Opin Support Palliat Care 4(1):16-18

9. Gerber DE (2008) Targeted therapies: a new generation of cancer treatments. Am Fam Physician 77(3):311-319

10. Widakowich C, De Castro G Jr, de Azambuja E et al (2007) Review: side effects of approved molecular targeted therapies in solid cancers. Oncologist 12(12):1443-1455

11. Lacouture ME, Reilly LM, Gerami P et al (2008) Hand foot skin reaction in cancer patients treated with the multikinase inhibitors sorafenib and sunitinib. Ann Oncol 19(11):1955-1961

12. Institute NC Targeted cancer therapies. National Cancer Institute. http://www.cancer.gov/cancertopics/factsheet/Therapy/targeted. Accessed November, 2010

13. Food and Drug Administration (2012) AstraZeneca Pharmaceuticals LP; Withdrawal of Approval of a New Drug Application for IRESSA.

14. European Medicines Agency (2009) Iressa. http:// www.ema.europa.eu/ema/index.jsp?curl=pages/medicines/human/ medicines/001016/human med 000857.jsp\&mid= WC0b01ac058001d124. Accessed 6/15/2012

15. Sackett DL, Straus SE, Richardson WS et al (2000) Evidencebased medicine: how to practice and teach EBM, 2nd edn. Churchill Livingstone, Edinburgh

16. Baar J, Silverman P, Lyons J et al (2009) A vasculature-targeting regimen of preoperative docetaxel with or without bevacizumab for locally advanced breast cancer: impact on angiogenic biomarkers. Clin Cancer Res 15(10):3583-3590

17. Fuchs CS, Marshall J, Mitchell E et al (2007) Randomized, controlled trial of irinotecan plus infusional, bolus, or oral fluoropyrimidines in first-line treatment of metastatic colorectal cancer: results from the BICC-C Study. J Clin Oncol 25(30):4779-4786

18. Giantonio BJ, Catalano PJ, Meropol NJ et al (2007) Bevacizumab in combination with oxaliplatin, fluorouracil, and leucovorin
(FOLFOX4) for previously treated metastatic colorectal cancer: results from the Eastern Cooperative Oncology Group Study E3200. J Clin Oncol 25(12):1539-1544

19. Herbst RS, O'Neill VJ, Fehrenbacher L et al (2007) Phase II study of efficacy and safety of bevacizumab in combination with chemotherapy or erlotinib compared with chemotherapy alone for treatment of recurrent or refractory non small-cell lung cancer. J Clin Oncol 25(30):4743-4750

20. Hochster HS, Hart LL, Ramanathan RK et al (2008) Safety and efficacy of oxaliplatin and fluoropyrimidine regimens with or without bevacizumab as first-line treatment of metastatic colorectal cancer: results of the TREE Study. J Clin Oncol 26(21):3523-3529

21. Hurwitz H, Fehrenbacher L, Novotny W et al (2004) Bevacizumab plus irinotecan, fluorouracil, and leucovorin for metastatic colorectal cancer. N Engl J Med 350(23):2335-2342

22. Hurwitz HI, Fehrenbacher L, Hainsworth JD et al (2005) Bevacizumab in combination with fluorouracil and leucovorin: an active regimen for first-line metastatic colorectal cancer. J Clin Oncol 23(15):3502-3508

23. Johnson DH, Fehrenbacher L, Novotny WF et al (2004) Randomized phase II trial comparing bevacizumab plus carboplatin and paclitaxel with carboplatin and paclitaxel alone in previously untreated locally advanced or metastatic non-small-cell lung cancer. J Clin Oncol 22(11):2184-2191

24. Kabbinavar F, Hurwitz HI, Fehrenbacher L et al (2003) Phase II, randomized trial comparing bevacizumab plus fluorouracil (FU)/ leucovorin (LV) with FU/LV alone in patients with metastatic colorectal cancer. J Clin Oncol 21(1):60-65

25. Kabbinavar FF, Schulz J, McCleod M et al (2005) Addition of bevacizumab to bolus fluorouracil and leucovorin in first-line metastatic colorectal cancer: results of a randomized phase II trial. J Clin Oncol 23(16):3697-3705

26. Kemeny NE, Jarnagin WR, Capanu M et al (2011) Randomized phase II trial of adjuvant hepatic arterial infusion and systemic chemotherapy with or without bevacizumab in patients with resected hepatic metastases from colorectal cancer. J Clin Oncol 29(7):884-889

27. Miles DW, Chan A, Dirix LY et al (2010) Phase III study of bevacizumab plus docetaxel compared with placebo plus docetaxel for the first-line treatment of human epidermal growth factor receptor 2-negative metastatic breast cancer. J Clin Oncol 28(20):3239-3247

28. Miller K, Wang M, Gralow J et al (2007) Paclitaxel plus bevacizumab versus paclitaxel alone for metastatic breast cancer. N Engl J Med 357(26):2666-2676

29. Miller KD, Chap LI, Holmes FA et al (2005) Randomized phase III trial of capecitabine compared with bevacizumab plus capecitabine in patients with previously treated metastatic breast cancer. J Clin Oncol 23(4):792-799

30. Moehler M, Sprinzl MF, Abdelfattah M et al (2009) Capecitabine and irinotecan with and without bevacizumab for advanced colorectal cancer patients. World J Gastroenterol 15(4):449-456

31. Reck M, von Pawel J, Zatloukal P et al (2009) Phase III trial of cisplatin plus gemcitabine with either placebo or bevacizumab as first-line therapy for nonsquamous non-small-cell lung cancer: AVAil. J Clin Oncol 27(8):1227-1234

32. Saltz LB, Clarke S, Diaz-Rubio E et al (2008) Bevacizumab in combination with oxaliplatin-based chemotherapy as first-line therapy in metastatic colorectal cancer: a randomized phase III study. J Clin Oncol 26(12):2013-2019

33. Sandler A, Gray R, Perry MC et al (2006) Paclitaxel-carboplatin alone or with bevacizumab for non-small-cell lung cancer. N Engl J Med 355(24):2542-2550

34. Stathopoulos GP, Batziou C, Trafalis D et al (2010) Treatment of colorectal cancer with and without bevacizumab: a phase III study. Oncology 78(5-6):376-381 
35. Tebbutt NC, Wilson K, Gebski VJ et al (2010) Capecitabine, bevacizumab, and mitomycin in first-line treatment of metastatic colorectal cancer: results of the Australasian Gastrointestinal Trials Group Randomized Phase III MAX Study. J Clin Oncol 28(19):3191-3198

36. Bokemeyer C, Bondarenko I, Makhson A et al (2009) Fluorouracil, leucovorin, and oxaliplatin with and without cetuximab in the firstline treatment of metastatic colorectal cancer. J Clin Oncol 27(5):663-671

37. Borner M, Koeberle D, Von Moos R et al (2008) Adding cetuximab to capecitabine plus oxaliplatin (XELOX) in firstline treatment of metastatic colorectal cancer: a randomized phase II trial of the Swiss Group for Clinical Cancer Research SAKK. Ann Oncol 19(7):1288-1292

38. Van Cutsem E, Kohne CH, Hitre E et al (2009) Cetuximab and chemotherapy as initial treatment for metastatic colorectal cancer. N Engl J Med 360(14):1408-1417

39. Vermorken JB, Mesia R, Rivera F et al (2008) Platinum-based chemotherapy plus cetuximab in head and neck cancer. N Engl J Med 359(11):1116-1127

40. Cappuzzo F, Ciuleanu T, Stelmakh L et al (2010) Erlotinib as maintenance treatment in advanced non-small-cell lung cancer: a multicentre, randomised, placebo-controlled phase 3 study. Lancet Oncol 11(6):521-529

41. Gatzemeier U, Pluzanska A, Szczesna A et al (2007) Phase III study of erlotinib in combination with cisplatin and gemcitabine in advanced non-small-cell lung cancer: the Tarceva Lung Cancer Investigation Trial. J Clin Oncol 25(12):1545-1552

42. Herbst RS, Prager D, Hermann R et al (2005) TRIBUTE: a phase III trial of erlotinib hydrochloride (OSI-774) combined with carboplatin and paclitaxel chemotherapy in advanced non-smallcell lung cancer. J Clin Oncol 23(25):5892-5899

43. Lilenbaum R, Axelrod R, Thomas S et al (2008) Randomized phase II trial of erlotinib or standard chemotherapy in patients with advanced non-small-cell lung cancer and a performance status of 2. J Clin Oncol 26(6):863-869

44. Mok TS, Wu YL, Yu CJ et al (2009) Randomized, placebocontrolled, phase II study of sequential erlotinib and chemotherapy as first-line treatment for advanced non-small-cell lung cancer. $\mathbf{J}$ Clin Oncol 27(30):5080-5087

45. Moore MJ, Goldstein D, Hamm J et al (2007) Erlotinib plus gemcitabine compared with gemcitabine alone in patients with advanced pancreatic cancer: a phase III trial of the National Cancer Institute of Canada Clinical Trials Group. J Clin Oncol 25(15):1960-1966

46. Shepherd FA, Rodrigues Pereira J, Ciuleanu T et al (2005) Erlotinib in previously treated non-small-cell lung cancer. N Engl J Med 353(2):123-132

47. Crino L, Cappuzzo F, Zatloukal P et al (2008) Gefitinib versus vinorelbine in chemotherapy-naive elderly patients with advanced non-small-cell lung cancer (INVITE): a randomized, phase II study. J Clin Oncol 26(26):4253-4260

48. Cufer T, Vrdoljak E, Gaafar R et al (2006) Phase II, open-label, randomized study (SIGN) of single-agent gefitinib (IRESSA) or docetaxel as second-line therapy in patients with advanced (stage IIIb or IV) non-small-cell lung cancer. Anticancer Drugs 17(4):401409

49. Giaccone G, Herbst RS, Manegold C et al (2004) Gefitinib in combination with gemcitabine and cisplatin in advanced nonsmall-cell lung cancer: a phase III trial-INTACT 1. J Clin Oncol 22(5):777-784

50. Goss G, Ferry D, Wierzbicki R et al (2009) Randomized phase II study of gefitinib compared with placebo in chemotherapy-naive patients with advanced non-small-cell lung cancer and poor performance status. J Clin Oncol 27(13):2253-2260

51. Herbst RS, Giaccone G, Schiller JH et al (2004) Gefitinib in combination with paclitaxel and carboplatin in advanced non- small-cell lung cancer: a phase III trial-INTACT 2. J Clin Oncol 22(5):785-794

52. Kelly K, Chansky K, Gaspar LE et al (2008) Phase III trial of maintenance gefitinib or placebo after concurrent chemoradiotherapy and docetaxel consolidation in inoperable stage III non-small-cell lung cancer: SWOG S0023. J Clin Oncol 26(15):2450-2456

53. Kim ES, Hirsh V, Mok T et al (2008) Gefitinib versus docetaxel in previously treated non-small-cell lung cancer (INTEREST): a randomised phase III trial. Lancet 372(9652):1809-1818

54. Lee DH, Park K, Kim JH et al (2010) Randomized phase III trial of gefitinib versus docetaxel in non-small cell lung cancer patients who have previously received platinum-based chemotherapy. Clin Cancer Res 16(4):1307-1314

55. Maemondo M, Inoue A, Kobayashi K et al (2010) Gefitinib or chemotherapy for non-small-cell lung cancer with mutated EGFR. N Engl J Med 362(25):2380-2388

56. Maruyama R, Nishiwaki Y, Tamura T et al (2008) Phase III study, $\mathrm{V}-15-32$, of gefitinib versus docetaxel in previously treated Japanese patients with non-small-cell lung cancer. J Clin Oncol 26(26):4244-4252

57. Mitsudomi T, Morita S, Yatabe Y et al (2010) Gefitinib versus cisplatin plus docetaxel in patients with non-small-cell lung cancer harbouring mutations of the epidermal growth factor receptor (WJTOG3405): an open label, randomised phase 3 trial. Lancet Oncol 11(2):121-128

58. Mok TS, Wu YL, Thongprasert S et al (2009) Gefitinib or carboplatin-paclitaxel in pulmonary adenocarcinoma. N Engl $\mathrm{J}$ Med 361(10):947-957

59. Morere JF, Brechot JM, Westeel V et al (2010) Randomized phase II trial of gefitinib or gemcitabine or docetaxel chemotherapy in patients with advanced non-small-cell lung cancer and a performance status of 2 or 3 (IFCT-0301 study). Lung Cancer 70(3):301-307

60. Takeda K, Hida T, Sato T et al (2010) Randomized phase III trial of platinum-doublet chemotherapy followed by gefitinib compared with continued platinum-doublet chemotherapy in Japanese patients with advanced non-small-cell lung cancer: results of a west Japan thoracic oncology group trial (WJTOG0203). J Clin Oncol 28(5):753-760

61. Thatcher N, Chang A, Parikh P et al (2005) Gefitinib plus best supportive care in previously treated patients with refractory advanced non-small-cell lung cancer: results from a randomised, placebo-controlled, multicentre study (Iressa Survival Evaluation in Lung Cancer). Lancet 366(9496):1527-1537

62. Tsuboi M, Kato H, Nagai K et al (2005) Gefitinib in the adjuvant setting: safety results from a phase III study in patients with completely resected non-small cell lung cancer. Anticancer Drugs 16(10):1123-1128

63. Cameron D, Casey M, Press M et al (2008) A phase III randomized comparison of lapatinib plus capecitabine versus capecitabine alone in women with advanced breast cancer that has progressed on trastuzumab: updated efficacy and biomarker analyses. Breast Cancer Res Treat 112(3):533-543

64. Di Leo A, Gomez HL, Aziz Z et al (2008) Phase III, double-blind, randomized study comparing lapatinib plus paclitaxel with placebo plus paclitaxel as first-line treatment for metastatic breast cancer. J Clin Oncol 26(34):5544-5552

65. Johnston S, Pippen J Jr, Pivot X et al (2009) Lapatinib combined with letrozole versus letrozole and placebo as first-line therapy for postmenopausal hormone receptor-positive metastatic breast cancer. J Clin Oncol 27(33):5538-5546

66. Aviles A, Nambo MJ, Castaneda C et al (2007) Rituximab and escalated chemotherapy in elderly patients with aggressive diffuse large-cell lymphoma: a controlled clinical trial. Cancer Biother Radiopharm 22(2):194-199

67. Aviles A, Nambo MJ, Neri N et al (2007) Dose dense (CEOP-14) vs dose dense and rituximab (CEOP-14 $+\mathrm{R})$ in high-risk diffuse large cell lymphoma. Med Oncol 24(1):85-89 
68. Buske C, Hoster E, Dreyling M et al (2009) The addition of rituximab to front-line therapy with $\mathrm{CHOP}$ (R-CHOP) results in a higher response rate and longer time to treatment failure in patients with lymphoplasmacytic lymphoma: results of a randomized trial of the German Low-Grade Lymphoma Study Group (GLSG). Leukemia 23(1):153-161

69. Coiffier B, Lepage E, Briere J et al (2002) CHOP chemotherapy plus rituximab compared with $\mathrm{CHOP}$ alone in elderly patients with diffuse large-B-cell lymphoma. N Engl J Med 346(4):235242

70. Coiffier B, Thieblemont C, Van Den Neste E et al (2010) Longterm outcome of patients in the LNH-98.5 trial, the first randomized study comparing rituximab-CHOP to standard CHOP chemotherapy in DLBCL patients: a study by the Groupe d'Etudes des Lymphomes de l'Adulte. Blood 116(12):2040-2045

71. Eve HE, Linch D, Qian W et al (2009) Toxicity of fludarabine and cyclophosphamide with or without rituximab as initial therapy for patients with previously untreated mantle cell lymphoma: results of a randomised phase II study. Leuk Lymphoma 50(2):211-215

72. Forstpointner R, Dreyling M, Repp R et al (2004) The addition of rituximab to a combination of fludarabine, cyclophosphamide, mitoxantrone (FCM) significantly increases the response rate and prolongs survival as compared with FCM alone in patients with relapsed and refractory follicular and mantle cell lymphomas: results of a prospective randomized study of the German LowGrade Lymphoma Study Group. Blood 104(10):3064-3071

73. Forstpointner R, Unterhalt M, Dreyling $M$ et al (2006) Maintenance therapy with rituximab leads to a significant prolongation of response duration after salvage therapy with a combination of rituximab, fludarabine, cyclophosphamide, and mitoxantrone (R-FCM) in patients with recurring and refractory follicular and mantle cell lymphomas: results of a prospective randomized study of the German Low Grade Lymphoma Study Group (GLSG). Blood 108(13):4003-4008

74. Ghielmini M, Schmitz SF, Cogliatti S et al (2005) Effect of single-agent rituximab given at the standard schedule or as prolonged treatment in patients with mantle cell lymphoma: a study of the Swiss Group for Clinical Cancer Research (SAKK). J Clin Oncol 23(4):705-711

75. Ghielmini M, Schmitz SF, Cogliatti SB et al (2004) Prolonged treatment with rituximab in patients with follicular lymphoma significantly increases event-free survival and response duration compared with the standard weekly $\mathrm{x} 4$ schedule. Blood 103(12):4416-4423

76. Habermann TM, Weller EA, Morrison VA et al (2006) Rituximab-CHOP versus CHOP alone or with maintenance rituximab in older patients with diffuse large B-cell lymphoma. J Clin Oncol 24(19):3121-3127

77. Haioun C, Mounier N, Emile JF et al (2009) Rituximab versus observation after high-dose consolidative first-line chemotherapy with autologous stem-cell transplantation in patients with poorrisk diffuse large B-cell lymphoma. Ann Oncol 20(12):19851992

78. Herold M, Haas A, Srock S et al (2007) Rituximab added to firstline mitoxantrone, chlorambucil, and prednisolone chemotherapy followed by interferon maintenance prolongs survival in patients with advanced follicular lymphoma: an East German Study Group Hematology and Oncology Study. J Clin Oncol 25(15):1986-1992

79. Hiddemann W, Kneba M, Dreyling M et al (2005) Frontline therapy with rituximab added to the combination of cyclophosphamide, doxorubicin, vincristine, and prednisone (CHOP) significantly improves the outcome for patients with advanced-stage follicular lymphoma compared with therapy with CHOP alone: results of a prospective randomized study of the German LowGrade Lymphoma Study Group. Blood 106(12):3725-3732
80. Kaplan LD, Lee JY, Ambinder RF et al (2005) Rituximab does not improve clinical outcome in a randomized phase 3 trial of CHOP with or without rituximab in patients with HIV-associated non-Hodgkin lymphoma: AIDS-Malignancies Consortium Trial 010. Blood 106(5):1538-1543

81. Lenz G, Dreyling M, Hoster E et al (2005) Immunochemotherapy with rituximab and cyclophosphamide, doxorubicin, vincristine, and prednisone significantly improves response and time to treatment failure, but not long-term outcome in patients with previously untreated mantle cell lymphoma: results of a prospective randomized trial of the German Low Grade Lymphoma Study Group (GLSG). J Clin Oncol 23(9):1984-1992

82. Marcus R, Imrie K, Belch A et al (2005) CVP chemotherapy plus rituximab compared with CVP as first-line treatment for advanced follicular lymphoma. Blood 105(4):1417-1423

83. Pfreundschuh M, Schubert J, Ziepert M et al (2008) Six versus eight cycles of bi-weekly CHOP-14 with or without rituximab in elderly patients with aggressive CD20+ B-cell lymphomas: a randomised controlled trial (RICOVER-60). Lancet Oncol 9(2):105-116

84. Pfreundschuh M, Trumper L, Osterborg A et al (2006) CHOPlike chemotherapy plus rituximab versus CHOP-like chemotherapy alone in young patients with good-prognosis diffuse large-Bcell lymphoma: a randomised controlled trial by the MabThera International Trial (MInT) Group. Lancet Oncol 7(5):379-391

85. Robak T, Dmoszynska A, Solal-Celigny P et al (2010) Rituximab plus fludarabine and cyclophosphamide prolongs progressionfree survival compared with fludarabine and cyclophosphamide alone in previously treated chronic lymphocytic leukemia. J Clin Oncol 28(10):1756-1765

86. Salles G, Mounier N, de Guibert S et al (2008) Rituximab combined with chemotherapy and interferon in follicular lymphoma patients: results of the GELA-GOELAMS FL2000 study. Blood 112(13):4824-4831

87. Sieniawski M, Staak O, Glossmann JP et al (2007) Rituximab added to an intensified salvage chemotherapy program followed by autologous stem cell transplantation improved the outcome in relapsed and refractory aggressive non-Hodgkin lymphoma. Ann Hematol 86(2):107-115

88. van Oers MH, Klasa R, Marcus RE et al (2006) Rituximab maintenance improves clinical outcome of relapsed/resistant follicular non-Hodgkin lymphoma in patients both with and without rituximab during induction: results of a prospective randomized phase 3 intergroup trial. Blood 108(10):3295-3301

89. van Oers MH, Van Glabbeke M, Giurgea L et al (2010) Rituximab maintenance treatment of relapsed/resistant follicular non-Hodgkin's lymphoma: long-term outcome of the EORTC 20981 phase III randomized intergroup study. J Clin Oncol 28(17):2853-2858

90. Abou-Alfa GK, Johnson P, Knox JJ, Capanu M, Davidenko I, Lacava J, Leung T, Gansukh B, Saltz LB (2010) Doxorubicin plus sorafenib vs doxorubicin alone in patients with advanced hepatocellular carcinoma: a randomized trial. JAMA 304(19):2154-2160

91. Cheng AL, Kang YK, Chen Z et al (2009) Efficacy and safety of sorafenib in patients in the Asia-Pacific region with advanced hepatocellular carcinoma: a phase III randomised, double-blind, placebo-controlled trial. Lancet Oncol 10(1):25-34

92. Escudier B, Eisen T, Stadler WM et al (2009) Sorafenib for treatment of renal cell carcinoma: final efficacy and safety results of the phase III treatment approaches in renal cancer global evaluation trial. J Clin Oncol 27(20):3312-3318

93. Escudier B, Szczylik C, Hutson TE et al (2009) Randomized phase II trial of first-line treatment with sorafenib versus interferon Alfa-2a in patients with metastatic renal cell carcinoma. J Clin Oncol 27(8):1280-1289

94. Llovet JM, Ricci S, Mazzaferro V et al (2008) Sorafenib in advanced hepatocellular carcinoma. N Engl J Med 359(4):378-390 
95. Buzdar AU, Ibrahim NK, Francis D et al (2005) Significantly higher pathologic complete remission rate after neoadjuvant therapy with trastuzumab, paclitaxel, and epirubicin chemotherapy: results of a randomized trial in human epidermal growth factor receptor 2-positive operable breast cancer. J Clin Oncol 23(16):3676-3685

96. Buzdar AU, Valero V, Ibrahim NK et al (2007) Neoadjuvant therapy with paclitaxel followed by 5 -fluorouracil, epirubicin, and cyclophosphamide chemotherapy and concurrent trastuzumab in human epidermal growth factor receptor 2-positive operable breast cancer: an update of the initial randomized study population and data of additional patients treated with the same regimen. Clin Cancer Res 13(1):228-233

97. Gasparini G, Gion M, Mariani L et al (2007) Randomized phase II trial of weekly paclitaxel alone versus trastuzumab plus weekly paclitaxel as first-line therapy of patients with Her-2 positive advanced breast cancer. Breast Cancer Res Treat 101(3):355-365

98. Gianni L, Eiermann W, Semiglazov V et al (2010) Neoadjuvant chemotherapy with trastuzumab followed by adjuvant trastuzumab versus neoadjuvant chemotherapy alone, in patients with HER2positive locally advanced breast cancer (the NOAH trial): a randomised controlled superiority trial with a parallel HER2negative cohort. Lancet 375(9712):377-384

99. Halyard MY, Pisansky TM, Dueck AC et al (2009) Radiotherapy and adjuvant trastuzumab in operable breast cancer: tolerability and adverse event data from the NCCTG Phase III Trial N9831. J Clin Oncol 27(16):2638-2644

100. Joensuu H, Bono P, Kataja V et al (2009) Fluorouracil, epirubicin, and cyclophosphamide with either docetaxel or vinorelbine, with or without trastuzumab, as adjuvant treatments of breast cancer: final results of the FinHer Trial. J Clin Oncol 27(34):5685-5692

101. Joensuu H, Kellokumpu-Lehtinen PL, Bono P et al (2006) Adjuvant docetaxel or vinorelbine with or without trastuzumab for breast cancer. N Engl J Med 354(8):809-820

102. Marty M, Cognetti F, Maraninchi D et al (2005) Randomized phase II trial of the efficacy and safety of trastuzumab combined with docetaxel in patients with human epidermal growth factor receptor 2-positive metastatic breast cancer administered as first-line treatment: the M77001 study group. J Clin Oncol 23(19):4265-4274

103. Piccart-Gebhart MJ, Procter M, Leyland-Jones B et al (2005) Trastuzumab after adjuvant chemotherapy in HER2-positive breast cancer. N Engl J Med 353(16):1659-1672

104. Procter M, Suter TM, de Azambuja E et al (2010) Longer-term assessment of trastuzumab-related cardiac adverse events in the Herceptin Adjuvant (HERA) trial. J Clin Oncol 28(21):3422-3428

105. Slamon DJ, Leyland-Jones B, Shak S et al (2001) Use of chemotherapy plus a monoclonal antibody against HER2 for metastatic breast cancer that overexpresses HER2. N Engl J Med 344(11):783-792

106. Smith I, Procter M, Gelber RD et al (2007) 2-year follow-up of trastuzumab after adjuvant chemotherapy in HER2-positive breast cancer: a randomised controlled trial. Lancet 369(9555):29-36

107. Spielmann M, Roche H, Delozier T et al (2009) Trastuzumab for patients with axillary-node-positive breast cancer: results of the FNCLCC-PACS 04 trial. J Clin Oncol 27(36):6129-6134

108. Tan-Chiu E, Yothers G, Romond E et al (2005) Assessment of cardiac dysfunction in a randomized trial comparing doxorubicin and cyclophosphamide followed by paclitaxel, with or without trastuzumab as adjuvant therapy in node-positive, human epidermal growth factor receptor 2-overexpressing breast cancer: NSABP B-31. J Clin Oncol 23(31):7811-7819

109. Dematteo RP, Ballman KV, Antonescu CR et al (2009) Adjuvant imatinib mesylate after resection of localised, primary gastrointestinal stromal tumour: a randomised, double-blind, placebocontrolled trial. Lancet 373(9669):1097-1104

110. Druker BJ, Guilhot F, O'Brien SG et al (2006) Five-year followup of patients receiving imatinib for chronic myeloid leukemia. $\mathrm{N}$ Engl J Med 355(23):2408-2417

111. Guilhot F, Druker B, Larson RA et al (2009) High rates of durable response are achieved with imatinib after treatment with interferon alpha plus cytarabine: results from the International Randomized Study of Interferon and STI571 (IRIS) trial. Haematologica 94(12):1669-1675

112. Hochhaus A, O'Brien SG, Guilhot F et al (2009) Six-year followup of patients receiving imatinib for the first-line treatment of chronic myeloid leukemia. Leukemia 23(6):1054-1061

113. O'Brien SG, Guilhot F, Larson RA et al (2003) Imatinib compared with interferon and low-dose cytarabine for newly diagnosed chronic-phase chronic myeloid leukemia. N Engl J Med 348(11):994-1004

114. Demetri GD, van Oosterom AT, Garrett CR et al (2006) Efficacy and safety of sunitinib in patients with advanced gastrointestinal stromal tumour after failure of imatinib: a randomised controlled trial. Lancet 368(9544):1329-1338

115. Motzer RJ, Hutson TE, Tomczak P et al (2009) Overall survival and updated results for sunitinib compared with interferon alfa in patients with metastatic renal cell carcinoma. J Clin Oncol 27(22):3584-3590

116. Feugier P, Van Hoof A, Sebban C et al (2005) Long-term results of the R-CHOP study in the treatment of elderly patients with diffuse large B-cell lymphoma: a study by the Groupe d'Etude des Lymphomes de l'Adulte. J Clin Oncol 23(18):4117-4126

117. Harandi A, Zaidi AS, Stocker AM et al (2009) Clinical efficacy and toxicity of anti-EGFR therapy in common cancers. J Oncol 2009:567486

118. Elez E, Macarulla T, Tabernero J (2008) Handling side-effects of targeted therapies: safety of targeted therapies in solid tumours. Ann Oncol 19(Suppl 7):vii146-vii152

119. Watters AL, Epstein JB, Agulnik M (2011) Oral complications of targeted cancer therapies: a narrative literature review. Oral Oncol 47(6):441-448

120. Sonis ST, Elting LS, Keefe D et al (2004) Perspectives on cancer therapy-induced mucosal injury: pathogenesis, measurement, epidemiology, and consequences for patients. Cancer 100(9 Suppl):1995-2025

121. Sonis ST (2009) Mucositis: the impact, biology and therapeutic opportunities of oral mucositis. Oral Oncol 45(12):1015-1020

122. Fromme EK, Eilers KM, Mori M et al (2004) How accurate is clinician reporting of chemotherapy adverse effects? A comparison with patient-reported symptoms from the Quality-of-Life Questionnaire C30. J Clin Oncol 22(17):3485-3490

123. Code of Federal Regulations Title 21, Part 314.510.

124. Code of Federal Regulations Title 21, Part 601.41.

125. Roberts TG Jr, Chabner BA (2004) Beyond fast track for drug approvals. N Engl J Med 351(5):501-505 